・研究报告・

$$
\begin{aligned}
& \text { 西南喀斯特地貌区两栖动物丰富度 } \\
& \text { 分布格局与环境因子的关系 } \\
& \text { 王 波 } 1,4 \text { 黄 勇 }{ }^{2} \text { 李家堂 }{ }^{3} \text { 戴 强 }{ }^{3} \text { 王跃招 }{ }^{3} \text { 杨道德 }{ }^{*} \\
& 2 \text { (广西中医药大学, 南宁 530200) } \\
& 3 \text { (中国科学院成都生物研究所, 成都 610041) } \\
& 4 \text { (广西渌金生态科技有限公司，南宁 530028) }
\end{aligned}
$$

\begin{abstract}
摘要: 物种丰富度分布格局的成因机制一直是宏观生态学研究的热点问题之一。中国西南地区喀斯特地貌区(以广 西、云南和贵州为主)是世界上面积最大的喀斯特地貌区, 也是全球范围内 34 个生物多样性热点地区之一。为了解 该区域两栖动物物种丰富度分布格局及其与环境因子之间的关系, 本研究根据中国科学院成都生物研究所标本 馆、中国科学院昆明动物研究所标本馆、广西壮族自治区自然博物馆和中南林业科技大学动物标本室收藏的标本 数据, 以及公开发表的文献数据, 共获得18,246条两栖动物记录(219个物种), 然后运用生态位模型估测每个物种 的潜在分布区, 并把每个物种的潜在分布区叠加起来, 最终得到该区域在 $10 \mathrm{~km} \times 10 \mathrm{~km}$ 生态位模型空间尺度上的 两栖物种丰富度地理分布格局图, 最后进行多元回归和模型选择分析。结果表明: 有12种两栖动物仅在喀斯特地 貌区分布, 占物种总数的 $5.48 \%$; 有 104 种两栖动物仅在非喀斯特地貌区分布, 占物种总数的 $47.49 \%$; 有 103 种两栖 动物在喀斯特地貌区和非喀斯特地貌区均有分布, 占物种总数的 $47.03 \%$; 两栖动物物种丰富度随纬度的增高而降 低; 地貌类型(喀斯特地貌和非喀斯特地貌)对两栖动物物种丰富度的分布格局有显著影响 ( $\chi^{2}=36.47, P<0.0001$ ), 但模型拟合效果差 $($ McFadden's Rho square $=0.0037)$ 。影响该区域两栖动物物种丰富度分布格局最大的环境因子是 年均降雨量 $\left(R^{2}=0.232, P<0.001\right)$, 其次是最干月平均降雨量 $\left(R^{2}=0.221, P<0.001\right)$ 。该区域两栖动物物种丰富度的 格局主要是由地貌和不同的环境因子共同相互作用的结果, 不过仍有相当一部分物种丰富度的分布格局未被解 释。因此, 要更全面地认识该区域两栖动物物种丰富度格局的形成机制, 有必要加强干扰、捕食、竞争等其他生 物因子的影响研究。
\end{abstract}

关键词: 生物地理学; 两栖动物; 物种多样性; 喀斯特地貌; 生态位模型

\title{
Amphibian species richness patterns in karst regions in Southwest China and its environmental associations
}

Bo Wang ${ }^{1,4}$, Yong Huang ${ }^{2}$, Jiatang $\mathrm{Li}^{3}$, Qiang Dai ${ }^{3}$, Yuezhao Wang ${ }^{3}$, Daode Yang ${ }^{1 *}$

1 Institute of Wildlife Conservation, Central South University of Forestry and Technology, Changsha 410004

2 Guangxi University of Chinese Medicine, Nanning 530200

3 Chengdu Institute of Biology, Chinese Academy of Sciences, Chengdu 610041

4 Guangxi Lujin Ecological Technology Company, Nanning 530028

\begin{abstract}
Patterns in the distribution of species richness have always been a central theme in macroecology. The karst landforms in Southwest China (mainly Guangxi, Yunnan and Guizhou provinces) are among the largest of the global biodiversity hotspots. In this study, we sought to understand spatial patterns of amphibian species richness and its relationship with environmental factors. We compiled a large dataset of 18,246 records of point location data for 219 amphibian species occurring in China. We retrieved this data from published literature, Herpetology museums of Chengdu Institute of Biology and Kunming Institute of Zoology, Chinese Academy of Sciences, Guangxi Zhuang Autonomous Region Museum of Nature and the Central
\end{abstract}

收稿日期: 2018-04-22; 接受日期: 2018-07-05

基金项目: 国家自然科学基金(31472021, 31460559)

* 通讯作者 Author for correspondence. E-mail: csfuyydd@126.com 
South University of Forestry and Technology, and published sources. We used this data to generate the potential distributions of each species using ecological niche modeling. We combined the potential distributions maps of all species into a composite map to describe species richness patterns on the grid cell of $10 \mathrm{~km} \times 10 \mathrm{~km}$, and then conducted multivariate regression and model selection. Our results showed that 12 species were distributed only in karst area, accounting for 5.48\% of the total species pool, 104 species were found in non-karst area (47.49\% of total species), and 103 species were found in both karst area and non-karst area (47.03\% of total species). Based on the raw data of museum collections data and MaxEnt species distribution modeling, we found that amphibian species richness in the study area decreased at higher latitudes. Karst landforms and non-karst landforms differed in their distribution patterns of amphibian species richness $\left(\chi^{2}=\right.$ 36.47, $P<0.0001$ ), but the model was a poor fit to the data (McFadden's Rho square $=0.0037)$. The most significant environmental predictors of species richness were mean annual rainfall $\left(R^{2}=0.232, P<0.001\right)$ and precipitation of driest Month $\left(R^{2}=0.221, P<0.001\right)$. The results based on model selection showed that underlying mechanisms related to landforms and different ecological hypotheses might simultaneously explain patterns of amphibian species richness in the study area. Future research should examine other biological factors such as interference, predation, and competition to understand the mechanisms controlling patterns of amphibian species richness.

Key words: biogeography; amphibia; species diversity; karst landforms; MaxEnt model

物种丰富度分布格局的成因机制一直是宏观 生态学研究的热点问题之一(Gaston, 2000), 一般认 为是受生物进化、历史事件、生态过程以及现代气 候等多种因素共同作用的结果(Gaston, 2000; Hawkins et al, 2007; Guo et al, 2013)。环境因素影响物种 丰富度分布格局的假说目前被广泛认可和讨论 (Terribile et al, 2009), 其中能量假说和生境异质性 假说受到广泛接受。能量假说认为, 物种丰富度主 要受能量控制, 能量越高的地区物种越丰富(Wright, 1983; Hawkins et al, 2003a)。生境异质性假说认为, 生境异质性高的地区能够提供更多的生态位，从而 更有利于物种共存, 物种丰富度也随之增加 (Shmida \& Wilson, 1985)。根据不同的能量形式, 能 量假说至少包括: 外部环境能量假说 (ambient-energy hypothesis)、水分-能量动态假说(water-energy balance hypothesis)和生产力假说(productivity hypothesis) (Hawkins et al, 2003b)。

两栖动物起源于距今 3.5 亿年前, 能同时适应 水中和陆地生活。两栖动物是变温动物, 对温度、 相对湿度、水分等环境因子的变化非常敏感, 这种 特殊的生物学和生态学特征被认为最适合探讨物 种丰富度分布格局与环境因子的关系(Stuart et al, 2004)。我们基于中国西南喀斯特地貌区(广西、云 南和贵州)的两栖动物物种分布数据库, 利用高分 辨率的气候、地形、植被等环境因素, 结合相关假 说探讨影响两栖动物丰富度格局形成的多种环境 因子, 以便了解该区域两栖动物物种丰富度分布格
局形成的机理。

\section{研究区域}

喀斯特地貌由特殊地形、地貌及相关的生态系 统组成(Ford \& Williams, 1989), 是可溶性岩石(大 多为石灰岩)经过溶蚀、冲蚀、潜蚀, 以及坡陷等作 用所形成的地表和地下形态的总称，又称岩溶地 貌。中国是世界喀斯特地貌分布面积最广的国家之 一，很多省份都有喀斯特地貌分布，且喀斯特分布 面积占中国国土面积近 $1 / 8$, 但以西南区的贵州、云 南、广西所占的总面积最大(熊康宁等, 2008), 约占 全国喀斯特地貌总面积的31.5\%。广西境内主要是 热带-亚热带喀斯特地貌, 而贵州和云南多为高原 喀斯特地貌。西南喀斯特地貌区具有特殊的地质、 气候、地理条件和干扰历史, 演化出了石面、土面、 石土面、石沟、石缝、石坑、石洞等复杂多样的小 生境类型，其景观异质性高，孕育了丰富的生物多 样性(王世杰等, 2007), 为中国亚热带喀斯特地区珍 稀濒危及特有种最丰富和集中的地区之一(余国睿, 2014) ${ }^{\circledR}$ 。

\section{材料和方法}

\section{1 物种分布数据收集}

通过多种途径收集该区域(主要是广西壮族自 治区、云南省和贵州省)分布的两栖动物物种数据,

(1) 余国睿 (2014) 中国南方喀斯特生物多样性及其世界遗产价值 研究. 硕士学位论文, 贵州师范大学, 贵阳. 
主要来自中国科学院成都生物研究所两栖爬行动 物标本馆、中国科学院昆明动物研究所标本馆、广 西壮族自治区自然博物馆和中南林业科技大学动 物标本室收藏的最新数据, 以及各种论文和著作的 数据, 如 《中国两栖动物及其分布彩色图鉴》(费梁 等, 2012)、《广西两栖动物彩色图鉴》(莫运明等, 2014)、《云南两栖爬行动物》(杨大同和饶定齐, 2008)、《贵州两栖动物志》(伍律等, 1987)、《湖 南动物志: 两栖纲》(沈猷慧等, 2014)。最终收集到 两栖动物记录数据共 18,246 条, 然后对物种的分类 和分布记录数据进行校对; 对孤立分布的数据和有 疑问的物种鉴定数据进行重新检查和校对。两栖动 物物种分类系统和最新发表或修订的物种信息, 以 费梁等 (2012) 和中国两栖类数据库 (http://www. amphibiachina.org/)新收录的数据为依据。最终构建 了在该区域分布的 219 种两栖类物种数据库(附录 1)。对于物种分布的经纬度数据, 尽可能地使用标 本馆或博物馆或者文献上的记录, 如没有记录则在 Google Earth根据地名查询。

\section{2 环境变量和数据来源}

参考已有研究, 本文采用 30 个环境变量(表1), 并根据能量假说、水分假说、生产力假说和生境异 质性假说分为4组(Currie, 1991; Kerr \& Packer, 1997; Rahbek \& Graves, 2001; Tognelli \& Kelt, 2004), 在 分析前把所有环境变量重投影和重采样到同物种 丰富度相同的等面积栅格系统。(1)能量假说采用与 该假说相关的15个环境变量(表1)。BIO1-BIO11的 相关温度数据来源于Worldclim-Global Climate data (http: //www.worldclim.org/), 空间分辨率均为 $1 \mathrm{~km}$ 。 潜在蒸散量(mean annual potential evapotranspiration, PET)表示理想状态下经蒸发和蒸腾从地表向大气 转移的最大水量, 主要由环境能量决定 (Currie, 1991), 数据来源于http://www.grid.unep.ch/data/grid/ gnv183.html, 空间分辨率为 30' (Ahn \& Tateishi, 1994)。年均日照时数 (mean annual sunshine, SUNP) 和年均霜日频率(mean annual frost-day frequency, FF)均是在1961-1990年之间，空间分辨率都为 $10^{\prime}$ (New et al, 2002), 年均风速 (mean annual wind speed, WIND)数据是在1981-1996年之间, 来源于 http://www.geodata.cn/Portal, 空间分辨率为 $500 \mathrm{~m}^{2}$ 。 (2)水分假说采用与该假说相关的 9 个环境变量(表1)。 降雨量相关的数据(BIO12-BIO19)来源于Worldclim-
Global Climate data, 空间分辨率均为 $1 \mathrm{~km}$ 。年均相 对湿度(mean annual relative humidity, REH) 数据是 在1961-1990年之间，空间分辨率都为10' (New et al, 2002)。(3)生产力假说采用3个环境变量, 即年均归 一化植被指数(normalized difference vegetation index, NDVI)、实际蒸散量(mean annual actual evapotranspiration, AET)和年均太阳辐射量(mean annual solar radiation, RAD)。年均归一化植被指数是在 1998-2008年之间的数据, 来源于国家自然科学基 金委员会“中国西部环境与生态科学数据中心” (http://westdc.westgis. ac.cn), 空间分辨率为 $1 \mathrm{~km}^{2}$ 。 实际蒸散量数据来源于http://www.grid.unep.ch/data/ grid/gnv183.html, 空间分辨率为30' (Ahn \& Tateishi, 1994)。年均太阳辐射量的数据是在1950-1980年之 间, 数据来源于http://www.geodata.cn/Portal, 空间分 辨率为 $1 \mathrm{~km}$ 。(4) 生境异质性假说采用3个环境变量, 即海拔 (elevation, ELE)、植被类型数 (vegetation, VEG)和地貌类型(landform, LANDF)。每个栅格的 植被类型数表示每个栅格内的地形复杂性和生境 复杂性。海拔数据来源于http://eros.usgs.gov/, 空间 分辨率为 30 '。植被类型数据来源于国家自然科学基 金委员会中国西部环境与生态科学数据中心 (http://westdc. westgis.ac.cn), 空间分辨率为 $1 \mathrm{~km} \times$ $1 \mathrm{~km}$ 。地貌类型只提取喀斯特地貌和非喀斯特地貌, 该数据来源于国家科技基础条件平台一国家地球 系统科学数据共享服务平台的“中国1:100万数字地 貌数据库” (http://www.geodata.cn/) (李吉均等, 2009)。

\section{3 生态位模型和物种丰富度}

\subsection{1 生态位模型的建立}

MaxEnt物种分布模型是目前使用最广泛的生 态位模型, 采用物种分布点数据和环境变量共同预 测物种潜在分布区(Phillips et al, 2006; Phillips \& Dudík, 2008; Jiménez-Valverde et al, 2011; Ahmed et $\mathrm{al}, 2015)$ 。将研究区域每个两栖动物物种的经纬度 和各环境变量数据导入MaxEnt 3.3 .3 (http:// biodiversityinformatics.amnh.org/open_source/maxent/)。随机 选取 75\%的分布点用于模型建立, 剩余25\%的分布 点用于模型验证, 最大迭代次数设定为 5,000 , 模型 重复运行 100 次, 对环境参数设置刀切法(Jackknife) 来评价各环境因子的权重, 其他选项默认。

选择受试者工作特征曲线(receiver operating 
表1 4个假说表征的环境变量

Table 1 Environmental variables represented by the four hypotheses

\begin{tabular}{|c|c|c|}
\hline $\begin{array}{l}\text { 相关假说 } \\
\text { Hypothesis }\end{array}$ & $\begin{array}{l}\text { 环境变量 } \\
\text { Environmental variable }\end{array}$ & $\begin{array}{l}\text { 变量缩写 } \\
\text { Abbreviation }\end{array}$ \\
\hline \multirow{16}{*}{$\begin{array}{l}\text { 能量假说 } \\
\text { Energy } \\
\text { availability }\end{array}$} & 年均温度 Annual mean temperature $\left({ }^{\circ} \mathrm{C}\right)$ & $\mathrm{BIO} 1$ \\
\hline & 平均日温差 Mean diurnal range $\left({ }^{\circ} \mathrm{C}\right)$ & $\mathrm{BIO} 2$ \\
\hline & 等温性 Isothermality $\left({ }^{\circ} \mathrm{C}\right)$ & $\mathrm{BIO} 3$ \\
\hline & 季节性温度变化 Temperature seasonality & $\mathrm{BIO} 4$ \\
\hline & $\begin{array}{l}\text { 最高气温 } \\
\text { Max temperature of warmest month }\left({ }^{\circ} \mathrm{C}\right)\end{array}$ & $\mathrm{BIO} 5$ \\
\hline & $\begin{array}{l}\text { 最低气温 } \\
\text { Min temperature of coldest month }\left({ }^{\circ} \mathrm{C}\right)\end{array}$ & $\mathrm{BIO} 6$ \\
\hline & 年均温差 Temperature annual range $\left({ }^{\circ} \mathrm{C}\right)$ & $\mathrm{BIO} 7$ \\
\hline & $\begin{array}{l}\text { 最湿季平均温度 } \\
\text { Mean temperature of wettest quarter }\left({ }^{\circ} \mathrm{C}\right)\end{array}$ & $\mathrm{BIO} 8$ \\
\hline & $\begin{array}{l}\text { 最干季平均温度 } \\
\text { Mean temperature of driest quarter }\left({ }^{\circ} \mathrm{C}\right)\end{array}$ & $\mathrm{BIO9}$ \\
\hline & $\begin{array}{l}\text { 最暖季平均温度 } \\
\text { Mean temperature of warmest quarter }\left({ }^{\circ} \mathrm{C}\right)\end{array}$ & $\mathrm{BIO} 10$ \\
\hline & $\begin{array}{l}\text { 最冷季平均温度 } \\
\text { Mean temperature of coldest quarter }\left({ }^{\circ} \mathrm{C}\right)\end{array}$ & BIO11 \\
\hline & $\begin{array}{l}\text { 年均日照时数(白昼长的百分比) } \\
\text { Mean annual sunshine (percent of } \\
\text { daylength) }\end{array}$ & SUNP \\
\hline & $\begin{array}{l}\text { 年均霜日频率 } \\
\text { Mean annual frost-day frequency (days) }\end{array}$ & $\mathrm{FF}$ \\
\hline & 年均潜在蒸散量 & PET \\
\hline & $\begin{array}{l}\text { Mean annual potential evapotranspiration } \\
(\mathrm{mm} / \mathrm{yr})\end{array}$ & \\
\hline & 年均风速 Mean annual wind speed (m/s) & WIND \\
\hline \multirow{9}{*}{$\begin{array}{l}\text { 水分假说 } \\
\text { Water } \\
\text { availability }\end{array}$} & $\begin{array}{l}\text { 年均降雨量 } \\
\text { Annual precipitation (mm/yr) }\end{array}$ & $\mathrm{BIO} 12$ \\
\hline & $\begin{array}{l}\text { 最湿月平均降雨量 } \\
\text { Precipitation of wettest month (mm/yr) }\end{array}$ & BIO13 \\
\hline & $\begin{array}{l}\text { 最干月平均降雨量 } \\
\text { Precipitation of driest month (mm/yr) }\end{array}$ & BIO14 \\
\hline & 季节性降雨量 Precipitation seasonality & BIO15 \\
\hline & $\begin{array}{l}\text { 最湿季平均降雨量 } \\
\text { Precipitation of wettest quarter (mm/yr) }\end{array}$ & BIO16 \\
\hline & $\begin{array}{l}\text { 最干季平均降雨量 } \\
\text { Precipitation of driest quarter (mm/yr) }\end{array}$ & BIO17 \\
\hline & $\begin{array}{l}\text { 最暖季平均降雨量 } \\
\text { Precipitation of warmest quarter (mm/yr) }\end{array}$ & BIO18 \\
\hline & $\begin{array}{l}\text { 最冷季平均降雨量 } \\
\text { Precipitation of coldest quarter (mm/yr) }\end{array}$ & BIO19 \\
\hline & $\begin{array}{l}\text { 年均相对湿度 } \\
\text { Mean annual relative humidity (\%) }\end{array}$ & REH \\
\hline \multirow{3}{*}{$\begin{array}{l}\text { 生产力假说 } \\
\text { Productive } \\
\text { energy }\end{array}$} & 归一化植被指数 & NDVI \\
\hline & $\begin{array}{l}\text { Normalized difference vegetation index } \\
\text { 年均实际蒸散量 } \\
\text { Mean annual actual evapotranspiration } \\
(\mathrm{mm} / \mathrm{yr})\end{array}$ & AET \\
\hline & $\begin{array}{l}\text { 年均太阳辐射量 } \\
\text { Mean annual solar radiation }\left(\mathrm{W} / \mathrm{m}^{2}\right)\end{array}$ & RAD \\
\hline \multirow{3}{*}{$\begin{array}{l}\text { 生境异质性 } \\
\text { 假说 } \\
\text { Habitat } \\
\text { heterogeneity }\end{array}$} & 海拔 Elevation & ELE \\
\hline & $\begin{array}{l}\text { 植被类型数 } \\
\text { Vegetation (number of vegetation } \\
\text { classes/quadrat) }\end{array}$ & VEG \\
\hline & 地貌类型 Landform & LANDF \\
\hline
\end{tabular}

characteristic curve, ROC)与横坐标围成的面积, 即 AUC (area under curve)值来评价模型预测结果的精 准度。根据该曲线下的面积值判定模型的精确度, 其评价标准为: AUC值在 0.5-0.6为不及格; $0.6-0.7$ 为较差; $0.7-0.8$ 为一般; $0.8-0.9$ 为良好; $0.9-1.0$ 为优 秀(Phillips et al, 2006)。值越接近于1, 说明模型预测 的结果越准确(Hanley \& Mcneil, 1982)。此外, 模型 输出的栖息地适宜度指数(habitat suitability index, HSI)为 $0-1$ 之间的栅格，值越接近于 1 , 表示越适合 物种分布。在ArcGIS中, 以Natural Breaks法将栖息 地适宜度指数进行重分类, 为了保守估计物种潜在 的分布区，平均适宜度指数 $\geq 0.5$ 的栅格作为物种 的潜在分布区，小于 0.5 的栅格作为不适合物种分 布的生境。

\subsection{2 物种丰富度计算}

通过同样的参数设置预测 219 个两栖动物物种 的潜在分布区，再把所有物种的潜在分布区叠加生 成一个潜在分布图。由于不同空间尺度或面积对物 种丰富度的地理分布格局形成因素有重要的影响 (Schoener, 1976), 为了消除不同的空间尺度或面积 对物种丰富度的影响，我们把研究范围划分为 $10 \mathrm{~km} \times 10 \mathrm{~km}$ 的等面积栅格进行分析。因海岸线及 边界地区的栅格不完整，可能给后续统计分析带来 偏差，我们仅保留面积大于完整栅格面积 $96 \%$ 的栅 格进行分析。同时为了消除岛屿的影响，将所有的 岛屿均删去, 这样剩下 7,791 个有效栅格。最后统计 每个栅格内出现的物种总数, 并作为每个栅格的物 种丰富度值。

\section{4 统计分析方法}

在某一地区收集到的物种数据越多, 而生态位 模型预测的该地区的物种丰富度也越高(Costa et al, 2007)。为了比较实际收集到的物种分布数据和生态 位模型预测的物种分布数据是否存在偏差, 生成了 实际收集数据的物种丰富度栅格图 $(10 \mathrm{~km} \times 10 \mathrm{~km})$, 然后和生态位模型预测的物种丰富度栅格图进行 比较 $(10 \mathrm{~km} \times 10 \mathrm{~km})$ 。

由于各环境变量之间有一定的相关性，首先对 环境变量进行相关性分析, 然后选择相关系数低的 变量 $(r<0.7)$ 并且每个假说中至少有 1 个变量代表, 最终选择的环境变量有 12 个(表2)。

为了满足数据的正态性，将物种丰富度进行以 10 为底的对数转换。当处理大尺度的生态数据时, 
表2 两栖类物种丰富度和变量的线性回归分析的AICc值、统计值 $(t) 、 R^{2}$ 和 $P$ 值

Table 2 Standardized regression coefficients of linear regression, $t$ statistics, $R^{2}$ and associated $P$-values for amphibian species richness against environmental predictors

\begin{tabular}{lllllll}
\hline 环境变量 Enviromental predictor & AICc & AAICc & Wi & $t$ & $R^{2}$ & $P$ \\
\hline 年均降雨量 Annual precipitation (mm/yr) & 41,710 & 0 & 1 & 48.465 & 0.232 & $<0.001$ \\
最月平均降雨量 Precipitation of driest month (mm/yr) & 41,820 & 110 & 0 & 46.963 & 0.221 & $<0.001$ \\
日照时数(白昼长的百分比) Mean annual sunshine (percent of daylength) & 43,021 & 1,311 & 0 & -27.903 & 0.091 & 0 \\
年均实际蒸散量 Mean annual actual evapotranspiration (mm/yr) & 43,071 & 1,361 & 0 & 26.895 & 0.085 & $<0.001$ \\
年均相对湿度 Mean annual relative humidity (\%) & 43,479 & 1,769 & 0 & 17.021 & 0.036 & 0 \\
年均风速 Mean annual wind speed & 43,666 & 1,956 & 0 & -9.861 & 0.012 & $<0.001$ \\
年均潜在蒸散量 Mean annual potential evapotranspiration (mm/yr) & 43,753 & 2,043 & 0 & 3.129 & 0.001 & 0.002 \\
年均温度 Annual mean temperature ( $\left.{ }^{\circ} \mathrm{C}\right)$ & 43,568 & 1,858 & 0 & 14.043 & 0.025 & $<0.001$ \\
植被类型数 Vegetation (number of vegetation classes/quadrat) & 43,758 & 2,048 & 0 & -2.251 & $<0.001$ & 0.024 \\
归一化植被指数 Normalized difference vegetation index & 43,761 & 2,051 & 0 & 1.38 & $<0.001$ & 0.168 \\
年均太阳辐射量 Mean annual solar radiation $\left(\mathrm{W} / \mathrm{m}^{2}\right.$ ) & 43,761 & 2,051 & 0 & -1.453 & $<0.001$ & 0.146 \\
\hline
\end{tabular}

物种丰富度数据、环境数据或两者之间普遍存在显 著的空间自相关问题(Legendre, 1993)。如果不能降 低空间自相关性，通常会降低残差样本的独立性， 在进行显著性检验时，会增加犯第一类错误的概率， 并倾向于得到更显著的结果(Legendre, 1993; Diniz-Filho et al, 2003)。Moran's I指数常被用来度量回 归残差的空间自相关性(Diniz-Filho et al, 2003)。 Moran's I指数的取值范围也是 -1 到 1 。- 1 意味着存在 强烈的负的空间自相关, 0 意味没有相关性, 而1则 意味存在强烈的正的空间自相关。

统计分析在SAM (Rangel et al, 2010)软件中完 成。本研究除对地貌类型采用Logistic回归分析外, 其他环境因子采用基于普通最小二乘法(ordinary least squares, OLS)的线性回归模型考察各环境因子 对两栖动物丰富度的解释能力。

此外, 为探讨哪一个假说能更好地解释两栖动 物丰富度分布格局, 对每个假说进行了多元回归分 析(表2), 除 4 个假说外, 另增加了一个混合模型, 即 把每个假说的所有环境变量放在一起分析。根据 Akaike信息量准则(Akaike information criterion, AIC) 筛选出最优模型(其AICc值最小)及其所包含的变量, 然后用候选模型和最优模型间的 AICc 值之差 $(\triangle \mathrm{AICc})$ 来衡量相关模型的拟合度。 $\Delta \mathrm{AICc}$ 之值越大, 所验证的模型中越不可能是最优模型。总之, 当 $\Delta \mathrm{AICc} \leq 2$ 时, 数据(或者证据)强力支持该模型; 当 $4 \leq \triangle \mathrm{AICc} \leq 7$ 时, 数据在一定程度上支持该模型; 当 $\Delta \mathrm{AICc}>10$ 时, 数据不支持该模型。对于模型选 择的不确定性, 用赤池权重(Akaike weights, Wi)估
计模型平均值(Burnham \& Anderson, 1998; Anderson et al, 2000)。

\section{3 结果}

\section{1 物种分布格局}

本文共统计 219 种两栖动物, 隶属 3 目 12 科 48 属, 占目前已知全国两栖类物种总数471种(http://www. amphibiachina.org/., 2018-03-27)的46.50\%。其中物 种数最多的目为无尾目, 有 191 种, 占物种总数的 $87.21 \%$; 其次为有尾目, 有 27 种, 占 $12.33 \%$; 蚓螈 目仅 1 种, 占 $0.46 \%$ 。物种最多的科为蛙科(57种), 占 物种总数的 $26.03 \%$; 其次为角蟾科(45种, 占物种 总数的 $20.55 \%$ ) 和树蛙科 (37 种, 占物种总数的 $16.89 \%)$ 。物种最多的属为臭蛙属(Odorrana), 有 24 种, 占物种总数的 $10.96 \%$; 其次为树蛙属 (Rhacophorus) (17种，占物种总数的 7.76\%) 和异角蟾属 (Xenophrys) (12种, 占物种总数的 $5.48 \%$ )。有 12 种两 栖类仅在喀斯特地貌区分布, 占物种总数的 $5.48 \%$; 有104种仅在非喀斯特地貌区分布, 占物种总数的 47.49\%; 有103种在喀斯特地貌区和非喀斯特地貌 区均有分布, 占物种总数的 $47.03 \%$ (附录1)。

实际收集到的经纬度点数据和经MaxEnt模型 预测的物种丰富度分布格局图均表明, 两栖动物物 种丰富度最高的地点主要出现在非喀斯特地貌区, 即广西大瑶山国家级自然保护区附近(图1); 喀斯 特地貌区两栖动物物种丰富度分布最高的地点主 要出现在广西弄岗国家级自然保护区附近(图1)。

此外, 经MaxEnt模型预测的物种丰富度分布 


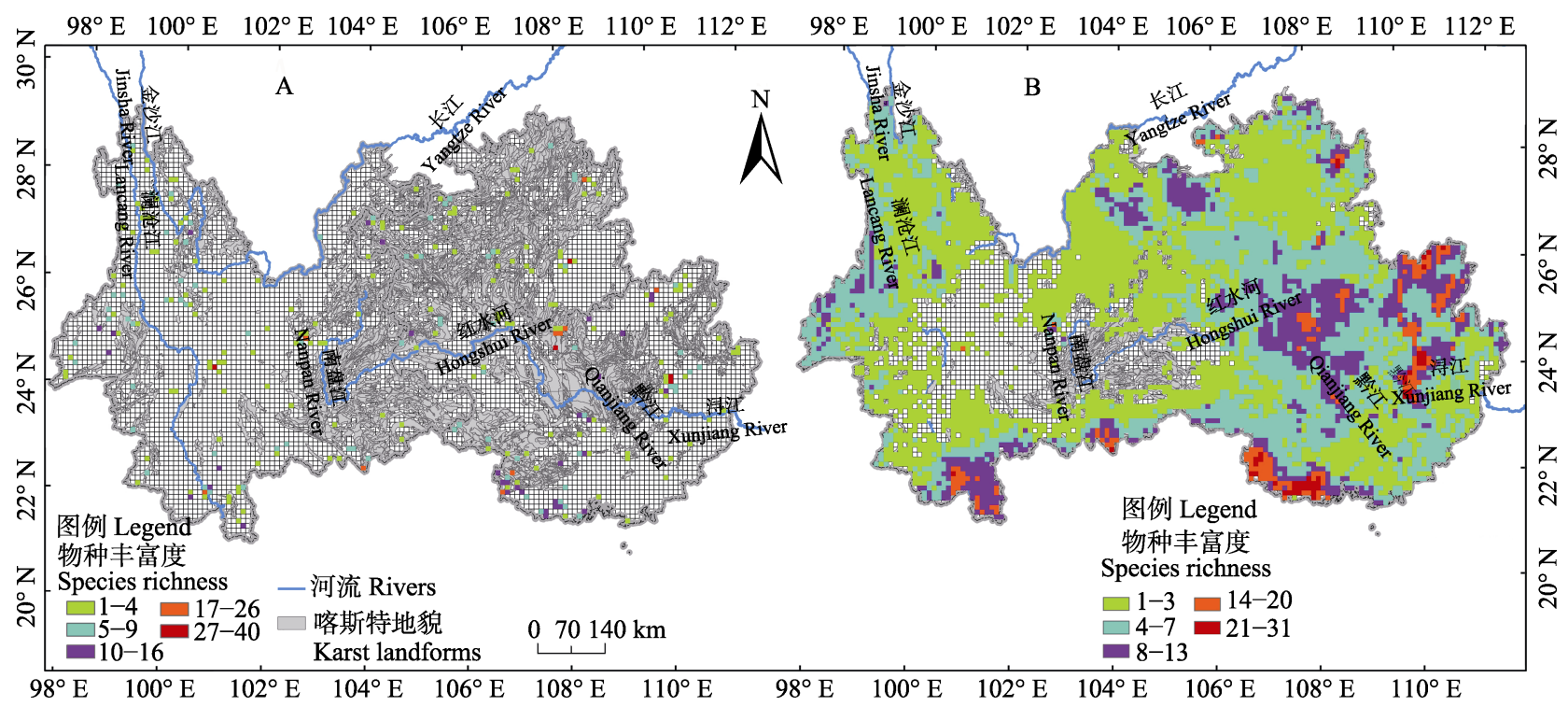

图1 西南喀斯特两栖动物物种丰富度格局图。A：基于实际收集的数据; B: 基于MaxEnt模型预测。每个栅格面积为 $10 \mathrm{~km} \times$ $10 \mathrm{~km}$, 空白栅格表示无物种分布记录或未收集到数据。

Fig. 1 Species distribution modeling of amphibians in Southwest China, based on (A) the raw data of museum collections data and (B) MaxEnt species distribution modeling. The area of each cell is $10 \mathrm{~km} \times 10 \mathrm{~km}$. Blank cells have no specimen based on the major collections.

格局的结果并未受到实际收集到的经纬度点数据 采样偏差的影响。从图1中可见, 经MaxEnt模型预 测的物种丰富度分布高的地方并不完全出现在实 际收集到的经纬度点数据多的地方，而未收集到经 纬度点数据的地方, 两栖动物的物种丰富度也很高, 如云南省的西双版纳地区和广西壮族自治区东部 的贺州市地区(图1)。

基于实际收集到的经纬度点数据, 研究区域内 的两栖动物物种丰富度在经度梯度上呈显著正相 关 $(t=3.38, d f=867, P=0.001)$, 即随着经度的增加, 物种丰富度显著增加; 而在纬度梯度上呈显著负相 关 $(t=-6.3, d f=867, P<0.001)$, 即随纬度的增加, 物种丰富度显著降低(图2)。基 MaxEnt模型预测的 物种丰富度, 两栖动物物种丰富度与经度呈显著正 相关 $(t=13.8, d f=5,200, P<0.001)$, 即随着经度的 增加, 物种丰富度显著增加; 而两栖动物物种丰富 度与纬度呈显著负相关 $(t=-13.2, d f=5,200, P<$ 0.001 ), 即随纬度的增加, 物种丰富度显著降低(图3)。

\section{2 环境因子的影响}

基于Moran's I指数, 回归分析能够降低两栖类 的物种丰富度和回归残差的空间自相关性(图4)。

Logistic回归模型分析表明地貌类型对两栖动物物 种丰富度分布格局有显著影响 $\left(\chi^{2}=36.47, P<0.0001\right)$, 优势比(odds ratio, OR)为 1.466 , 然而模型总体拟合
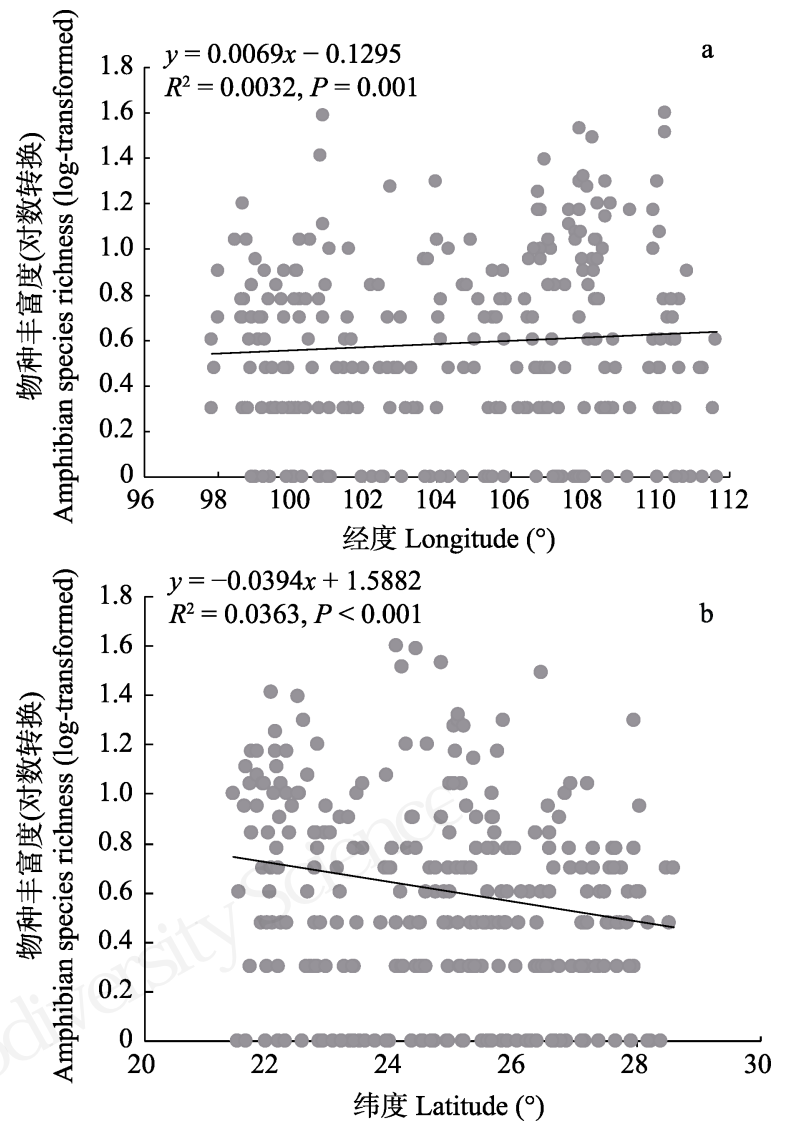

图2 基于实际收集到的经纬度点数据的两栖类物种丰富度 与经度(a)和纬度(b)的关系

Fig. 2 The relationships between amphibian richness and longitude (a) and latitude (b) based on the raw data of museum collections 

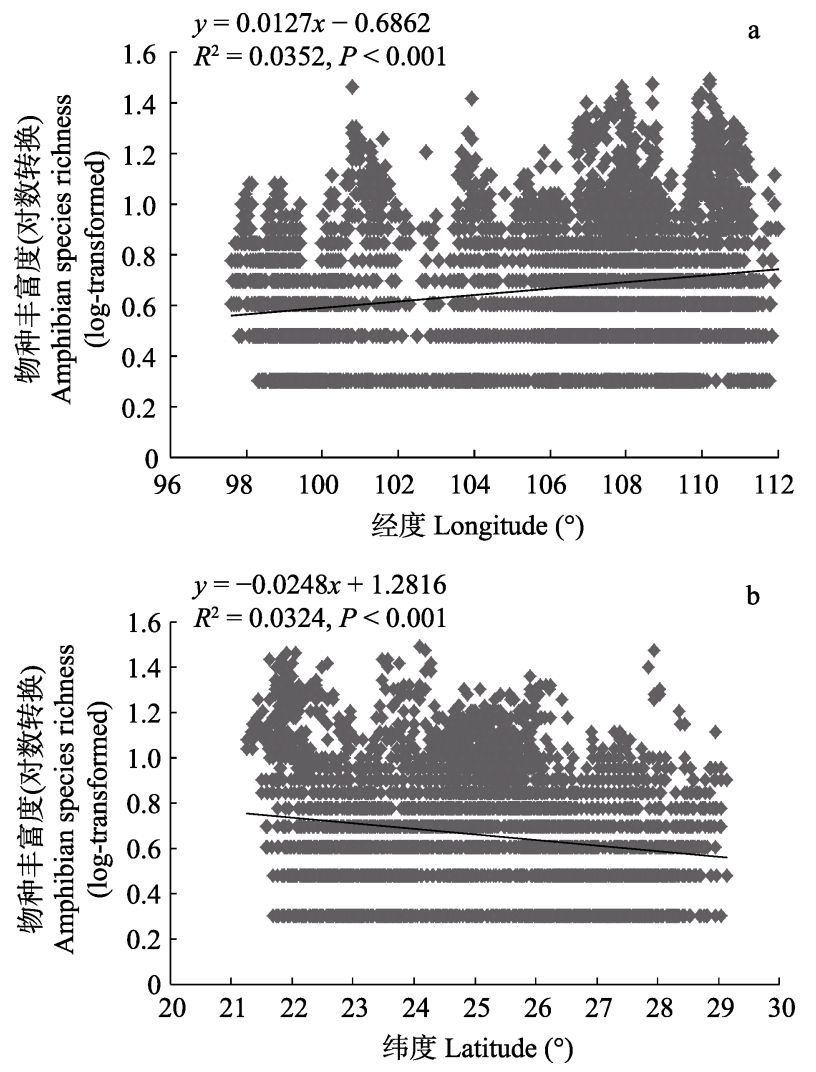

图3 基于MaxEnt模型预测的两栖类物种丰富度与经度(a) 和纬度(b)的关系

Fig. 3 The relationships between amphibian richness and longitude (a) and latitude (b) based on MaxEnt species distribution modeling

优度(McFadden's Rho square)为 0.0037 , 模型拟合效 果欠佳。线性回归模型分析表明, 根据最小的 Akaike信息量准则(AICc), 水分假说中的年均降雨 量(BIO12)对两栖动物物种丰富度的影响最优, 解 释了 $23.2 \%$ 的变异; 其次是最干月平均降雨量
(BIO14) (表2), 解释了 $22.1 \%$ 的变异。在能量因子中, 虽然日照时数(SUNP)的AIC值较低, 但对两栖动物 物种丰富度的影响较小, 解释度为 $9.1 \%$ 。在生产力 因子中, 实际蒸散量(AET)的AIC值最低, 同样对两 栖动物物种丰富度的影响较小, 解释度为 $8.5 \%$ 。单 个生境异质性因子对两栖动物物种丰富度的影响 极小(植被类型数, $\left.R^{2}<0.001, P=0.024\right)$ (表2)。

\section{3 模型选择}

基于模型选择方法，混合模型(包括所有环境 因子)的AICc值最低, 赤池权重为 1 (表3), 因此是最 优解释两栖动物物种丰富度格局的模型, 能解释丰 富度空间变异的 $42.5 \%$, 而其他模型(如能量假说， 水分假说、生产力假说和生境异质性假说)的 $\Delta$ 值都 大于10且赤池权重很低(表3)。

\section{4 讨论}

\section{1 两栖动物物种丰富度格局及其解释}

本文结果表明，不管是基于实际收集的物种数 据，还是基于MaxEnt模型预测的物种丰富度，两栖 动物物种丰富度随纬度的增加而降低, 这与其他地 区的研究结果一致，同时从另一方面也预示 MaxEnt模型的预测结果不因数据收集不均匀性而 出现偏差。之前曾有报道认为桂西南喀斯特山地既 是广西生物多样性热点区域之一，也是我国生物多 样性3个特有分布中心之一(苏宗明和李先琨，2003; Hou et al, 2010)。在本研究中也得到验证, 研究范围 内的两栖动物物种丰富度最高的地方均出现在广 西大瑶山国家级自然保护区和广西弄岗国家级自 然保护区附近。然而，不管是基于实际收集的物种

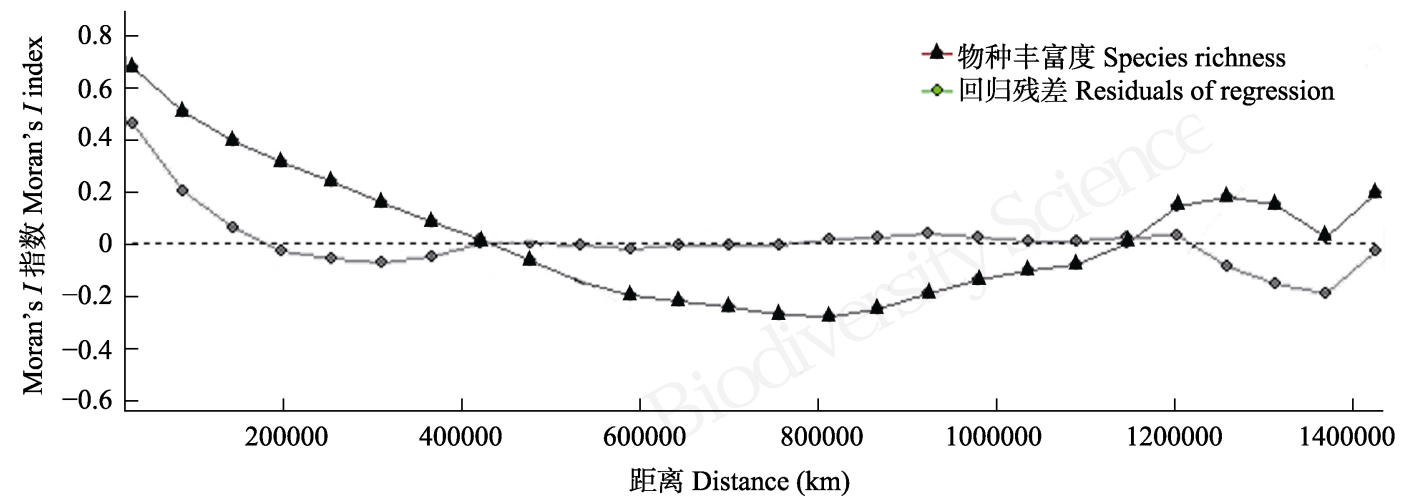

图4 两栖类的物种丰富度和环境变量的回归残差的Moran's I指数图

Fig. 4 Moran's I index correlogram for amphibian species richness and the residuals of multiple regression with environmental predictors 
表3 基于模型选择方法的每种假说的AICc值和调整 $R^{2}$ 值

Table 3 AICc value and adjusted $R^{2}$ value for each hypothesis based on model selection approach

\begin{tabular}{|c|c|c|c|c|c|}
\hline 假说 Hypothesis & $R^{2}$ & AICc & $\triangle \mathrm{AICc}$ & $K$ & Wi \\
\hline $\begin{array}{l}\text { 生产力假说 } \\
\text { Productivity energy }\end{array}$ & 0.004 & 6,908 & 4,268 & 4 & 0 \\
\hline $\begin{array}{l}\text { 生境异质性假说 } \\
\text { Habitat heterogeneity }\end{array}$ & 0.005 & 6,898 & 4,258 & 3 & 0 \\
\hline 能量假说 Ambient energy & 0.173 & 5,462 & 2,822 & 5 & 0 \\
\hline $\begin{array}{l}\text { 水分-能量假说 } \\
\text { Water-energy balance hypothesis }\end{array}$ & 0.34 & 3,706 & 1,066 & 4 & 0 \\
\hline 混合模型 Mixed model* & 0.425 & 2,640 & 0 & 12 & 1 \\
\hline
\end{tabular}

$\triangle \mathrm{AICc}$ 表示与最优模型的AICc差值, Wi是Akaike的权重, $K$ 表示模型 的变量数, 包括截距。

The model with the lowest AICc value was the most parsimonious one among the fitted models and was selected (marked in asterisk). In each hypothesis, the corrected Akaike Information Criterion (AICc) value, $R^{2}$ and Akaike weight (Wi) were given; $\triangle \mathrm{AICc}$ value is the AICc value difference between the representation and the optimal model. $K$ was the number of variables of the model, including intercept.

数据或者MaxEnt模型的预测结果, 物种丰富度分 布格局除经纬度因素外，都还受到其他因素影响。

环境因子对于物种丰富度格局的形成很重要 (Powney et al, 2010)。不同类群的物种丰富度与环境 因子关系的复杂性，可能与各类群独特的进化历史 及生理适应有关，这在某些类群中表现得尤为突 出。如在对单个环境因子的分析中, 年均降雨量是 影响两栖动物物种丰富度格局形成的最大因素, 这 与对其他地区(不管是在局部、区域、全球尺度上) 的研究结果“两栖动物物种丰富度与水分的相关性 更强”是一致的(Schall \& Pianka, 1978; Hawkins et al, 2003b; Buckley \& Jetz, 2007; 郑智等, 2014)。从两栖 动物的生理机能来看, 这是合理的。两栖动物皮肤 裸露, 均需要依赖于湿润的环境。幼体生活在水中, 成体大多数生活在陆地上, 少数种类生活在水中, 但成体一般生活在潮湿凉爽的环境中。由此可见, 这种分布格局的限制主要是对两栖动物生理需求 的直接效应导致, 而不是对两栖动物食物可利用性 或生境结构的间接需求导致。

\section{2 喀斯特地貌对两栖动物物种丰富度格局影响 有限}

中国西南喀斯特区域气候温和, 并且广泛分布 着山地、峰林、峰丛、洼地、溶洞、天坑、地上和 地下河流等多种地貌形态，以及独特的岛屿状生境， 形成了多种多样的地域性小气候, 这些都为物种的 隔离分化提供了有利条件, 一直以来都被认为对生
物多样性和物种的空间分布产生重要影响(袁铁象 等, 2014; Luo et al, 2016)。本结果表明地貌对两栖动 物的丰富度分布格局虽有影响, 但模型效果很差, 这说明除地貌因素外，还存在对两栖动物丰富度分 布格局有影响的其他因素。究其主要原因, 一方面 可能与两栖动物的生理需求有关; 另一方面, 研究 区域的喀斯特地貌是世界上湿润热带到亚热带的 喀斯特景观, 受第四纪冰川作用影响较小，区域内 并未形成众多的特有种, 这意味着喀斯特地貌形成 的生境异质性对两栖动物丰富度分布格局形成的 隔离分化作用有限。因此，将来有必要获取更多更 精细的数据, 进一步提升地貌对两栖动物物种丰富 度分布格局的影响精度。喀斯特地貌地区两栖动物 丰富度的分布格局不仅仅是各类群进化和适应环 境的结果, 也是喀斯特和非喀斯特地貌的地形和气 候条件所致。

\section{3 环境因素间共同作用影响两栖动物物种丰富} 度格局

物种丰富度地理分布格局的形成是各种因素 相互作用的结果(Gaston, 2000)。虽然代表水分因子 的年均降雨量在单个环境因子分析中，对两栖动物 物种丰富度的解释度最高, 不过本研究结果也显示 两栖动物的物种丰富度与多个环境因子具有显著 相关性, 很明显是各种环境因素相互作用决定了物 种丰富度分布格局。这在模型选择分析中也得到了 验证, 如混合模型是解释两栖动物的物种丰富度格 局的最优模型，这意味着不同生态假说或者多个环 境因素并不是相互排斥的，而是共同作用影响了两 栖动物物种丰富度格局(表2,3)。这与以前的一些研 究认为多个假说共同作用解释物种分布格局的结 果相符(Bohning-Gaese, 1997; Andrews \& O’Brien, 2000; Costa et al, 2007; Huang et al, 2011)。

此外, 最优线性模型对两栖动物物种丰富度格 局的解释率偏低, 可见仍有相当一部分物种丰富度 的分布格局未被解释。这说明，除了本文研究涉及 的经纬度、地貌和环境因素外，仍有一些可能影响 物种丰富度空间分布的因素未被涉及，如生物因素 (干扰、捕食、竞争等)以及区域历史对物种丰富度 格局形成与演化的影响(Ricklefs, 1987; Hawkins et al, 2003a; Buckley \& Jetz, 2007); 将来进一步对这 些因素的研究, 有助于更全面地认识两栖动物物种 丰富度格局的形成机制(Andrews \& O’Brien, 2000; 
Badgley \& Fox, 2000; Ruggiero \& Kitzberger, 2004)。

致谢: 感谢中国科学院成都生物研究所陈跃英副研 究员, 中国科学院昆明动物研究所刘硕助理研究 员、广西自然博物馆莫运名研究馆员在数据收集和 分析等方面提供的大力帮助和支持，感谢国家科技 基础条件平台一国家地球系统科学数据共享服务 平台 (http://www.geodata.cn)提供数据支撑!

\section{参考文献}

Ahmed SE, McInerny G, O’Hara K, Harper R, Salido L, Emmott S, Joppa LN (2015) Scientists and software-surveying the species distribution modelling community. Diversity and Distributions, 21, 258-267.

Ahn CH, Tateishi R (1994) Development of a global 30-minute grid potential evapotranspiration data set. Journal of the Japan Society of Photogrammetry, 33, 12-21.

Anderson DR, Burnham KP, Thompson WL (2000) Null hypothesis testing: Problems, prevalence, and an alternative. Journal of Wildlife Management, 64, 912-923.

Andrews P, O’Brien EM (2000) Climate, vegetation, and predictable gradients in mammal species richness in southern Africa. Journal of Zoology, 251, 205-231.

Badgley C, Fox DL (2000) Ecological biogeography of North American mammals: Species density and ecological structure in relation to environmental gradients. Journal of Biogeography, 27, 1437-1467.

Bohning-Gaese K (1997) Determinants of avian species richness at different spatial scales. Journal of Biogeography, 24, 49-60.

Buckley LB, Jetz W (2007) Environmental and historical constraints on global patterns of amphibian richness. Proceedings of the Royal Society B: Biological Sciences, 274, 1167-1173.

Burnham KP, Anderson DR (1998) Model Selection and Inference: A Practical in Formation Theoretic Approach. Springer-Verlag, New York.

Costa GC, Nogueira C, Machado RB, Colli GR (2007) Squamate richness in the Brazilian Cerrado and its environmental-climatic associations. Diversity and Distributions, 6, 714-724.

Currie DJ (1991) Energy and large-scale patterns of animaland plant-species richness. The American Naturalist, 137, 27-49.

Diniz-Filho JAF, Bini LM, Hawkins BA (2003) Spatial autocorrelation and red herrings in geographical ecology. Global Ecology \& Biogeography, 12, 53-64.

Fei L, Ye CY, Jiang JP (2012) Colored Atlas of Chinese Amphibians and Their Distributions. Sichuan Science and Technology Press, Chengdu. (in Chinese) [费梁, 叶昌媛,
江建平 (2012) 中国两栖动物及其分布彩色图鉴. 四川 科学技术出版社, 成都.]

Ford DC, Williams PW (1989) Karst Geomorphology and Hydrology. Unwin Hyman, London.

Gaston KJ (2000) Global patterns in biodiversity. Nature, 405, 220-227.

Guo Q, Kelt DA, Sun Z, Liu H, Hu L, Ren H, Wen J (2013) Global variation in elevational diversity patterns. Scientific Reports, 3, 3007.

Hanley JA, Mcneil BJ (1982) The meaning and use of the area under a Receiver Operating Characteristic (ROC) curve. Radiology, 143, 29-36.

Hawkins BA, Diniz-Filho JA, Jaramillo CA, Soeller SA (2007) Climate, niche conservatism, and the global bird diversity gradient. The American Naturalist, 170, S16-S27.

Hawkins BA, Field R, Cornell HV, Currie DJ, Guegan JF, Kaufman DM, Kerr JT, Mittelbach GG, Oberdorff T, O’Brien EM, Porter EE, Turner JRG (2003b) Energy, water, and broad-scale geographic patterns of species richness. Ecology, 84, 3105-3117.

Hawkins BA, Porter EE, Diniz JAF (2003a) Productivity and history as predictors of the latitudinal diversity gradient of terrestrial birds. Ecology, 84, 1608-1623.

Hou MF, López-pujol J, Qin HN, Wang LS, Liu Y (2010) Distribution pattern and conservation priorities for vascular plants in Southern China: Guangxi Province as a case study. Botanical Studies, 51, 377-386.

Huang Y, Dai Q, Chen Y, Wan HF, Li JT, Wang YZ (2011) Lizard species richness patterns in China and its environmental associations. Biodiversity and Conservation, 7, 1399-1414.

Jiménez-Valverde A, Peterson AT, Soberón J, Overton JM, Aragón P, Lobo JM (2011) Use of niche models in invasive species risk assessments. Biological Invasions, 13, 2785-2797.

Kerr JT, Packer L (1997) Habitat heterogeneity as a determinant of mammal species richness in high-energy regions. Nature, 385, 252-254.

Legendre P (1993) Spatial autocorrelation: Trouble or new paradigm. Ecology, 74, 1659-1673.

Li JJ, Zhou CH, Cheng WM (2009) 1 : 1000000 Geomorphological Atlas of the People's Republic of China. Science Press, Beijing. (in Chinese) [李吉均, 周成虎, 程维明 (2009) 中华人民共和国1：100万地貌图. 科学出版社, 北京.]

Luo ZH, Tang SH, Jiang ZG, Chen J, Fang HX, Li CW (2016) Conservation of terrestrial vertebrates in a global hotspot of karst area in Southwestern China. Scientific Reports, 6, 25717.

Mo YM, Wei ZY, Chen WC (2014) Color Atlas of Amphibians in Guangxi. Guangxi Science and Technology Press, Nanning. (in Chinese) [莫运明，韦振逸，陈伟才 (2014) 广西 两栖动物彩色图鉴. 广西科学技术出版社, 南宁.] 
New M, Lister D, Hulme M, Makin I (2002) A high-resolution data set of surface climate over global land areas. Climate Research, 21, 1-25.

Phillips SJ, Anderson RP, Schapire RE (2006) Maximum entropy modeling of species geographic distributions. Ecological Modelling, 190, 231-259.

Phillips SJ, Dudík MM (2008) Modeling of species distributions with Maxent: New extensions and a comprehensive evaluation. Ecography, 31, 161-175.

Powney GD, Grenyer R, Orme CDL, Owens IPF, Meiri S (2010) Hot, dry and different Australian lizard richness is unlike that of mammals, amphibians, and birds. Global Ecology \& Biogeography, 19, 386-396.

Rahbek C, Graves GR (2001) Multiscale assessment of patterns of avian species richness. Proceedings of the National Academy of Sciences, USA, 98, 4534-4539.

Rangel TF, Diniz-Filho JAF, Bini LM (2010) SAM: A comprehensive application for spatial analysis in macroecology. Ecography, 33, 46-50.

Ricklefs RE (1987) Community diversity: Relative roles of local and regional processes. Science, 235, 167-171.

Ruggiero A, Kitzberger T (2004) Environmental correlates of mammal species richness in South America: Effects of spatial structure, taxonomy and geographic range. Ecography, 27, 401-417.

Schall JJ, Pianka ER (1978) Geographical trends in numbers of species. Science, 201, 679-686.

Schoener TW (1976) The species-area relationship within archipelagoes: Models and evidence from island birds. Proceedings of XVI International Ornithological Congress, Australian Academy of Science, Canberra, Australia.

Shen YH, Yang DD, Mo XY (2014) Fauna of Hunan: Amphibian. Hunan Science and Technology Press, Changsha. (in Chinese) [沈猷慧, 杨道德, 莫小阳 (2014) 湖南动物 志: 两栖纲. 湖南科学技术出版社, 长沙.]

Shmida A, Wilson MV (1985) Biological determinants of species diversity. Journal of Biogeography, 12, 1-20.

Stuart SN, Chanson JS, Cox NA, Young BE, Rodrigues AS, Fischman DL, Waller RW (2004) Status and trends of amphibian declines and extinctions worldwide. Science, 306, 1783-1786.

Su ZM, Li XK (2003) The types of natural vegetation in karst region of Guangxi and its classified system. Guihaia, 23, 289-293. (in Chinese with English abstract) [苏宗明, 李先 琨 (2003) 广西岩溶植被类型及其分类系统. 广西植物, 23, 289-293.]
Terribile LC, Olalla-Tárraga MA, Morales-Castilla I, Rueda M, Vidanes RM, Rodríguez MA, Diniz-Filho JA (2009) Global richness patterns of venomous snakes reveal contrasting influences of ecology and history in two different clades. Oecologia, 159, 617-626.

Tognelli MF, Kelt DA (2004) Analysis of determinants of mammalian species richness in South America using spatial autoregressive models. Ecography, 27, 427-436

Wang SJ, Lu HM, Zhou YC, Xie LP, Xiao DA (2007) Spatial variability of soil organic carbon and representative soil sampling method in Maolan karst virgin forest. Acta Pedologica Sinica, 44, 475-483. (in Chinese with English abstract) [王世杰, 卢红梅, 周运超, 谢丽萍, 肖德安 (2007) 茂兰喀斯特原始森林土壤有机碳的空间变异性与代表性 土样采集方法. 土壤学报, 44, 475-483.]

Wright DH (1983) Species-energy theory: An extension of species-area theory. Oikos, 41, 496-506.

Wu L, Dong Q, Xu RH (1987) Amphibians in Guizhou. Guizhou People’s Press, Guiyang. (in Chinese) [伍律, 董谦, 须润华 (1987) 贵州两栖类志. 贵州人民出版社, 贵阳.]

Xiong KN, Xiao SZ, Liu ZQ, Chen PD (2008) Comparative analysis on world natural heritage value of South China Karst. Engineering Science, 10, 17-28. (in Chinese with English abstract) [熊康宁, 肖时珍, 刘子琦, 陈品冬 (2008) “中国南方喀斯特”的世界自然遗产价值对比分析. 中国工程科学, 10, 17-28.]

Yang DT, Rao DQ (2008) Amphibians and Reptiles in Yunnan. Yunnan Science and Technology Press, Kunming. (in Chinese) [杨大同, 饶定齐 (2008) 云南两栖爬行动物. 云南 科技出版社, 昆明.]

Yuan TX, Zhang HP, Ou ZY, Tan YB (2014) Effects of topography on the diversity and distribution pattern of ground plants in karst montane forests in Southwest Guangxi, China. Chinese Journal of Applied Ecology, 25, 2803-2810. (in Chinese with English abstract) [袁铁象, 张合平, 欧芷 阳, 谭一波 (2014) 地形对桂西南喀斯特山地森林地表 植物多样性及分布格局的影响. 应用生态学报, 25 , 2803-2810.]

Zheng Z, Gong DJ, Sun CX, Li XJ, Li WJ (2014) Elevational pattern of amphibian and reptile diversity in Qinling Range and explanation. Biodiversity Science, 22, 596-607. (in Chinese with English abstract) [郑智, 龚大洁, 孙呈祥, 李 晓军, 李万江 (2014) 秦岭两栖、爬行动物物种多样性海 拔分布格局及其解释. 生物多样性, 22, 596-607.]

(责任编委: 李义明 责任编辑: 间文杰)

\section{附录 Supplementary Material}

\section{附录1 西南喀斯特地貌区两栖动物物种名录}

Appendix 1 List of amphibian species in karst regions in Southwest China http://www.biodiversity-science.net/fileup/PDF/2018125-1.pdf 
王波, 黄勇, 李家堂, 戴强, 王跃招, 杨道德. 西南喀斯特地貌区两栖动物丰富度分布格局与环境因子的关 系. 生物多样性, 2018, 26 (9): 941-950.

http://www.biodiversity-science.net/CN/10.17520/biods.2018125

\section{附录1 西南喀斯特地貌区两栖动物物种名录}

Appendix1 List of amphibian species in karst regions in Southwest China

\begin{tabular}{|c|c|c|c|c|}
\hline & & 属名 & 物种名 & 分布 \\
\hline & & Genus & Species & Distribution \\
\hline 蚓螈目 & Gymnophiona & & & \\
\hline 鱼螈科 & Ichthyophiidae & 鱼螈属 Ichthyophis & 1 版纳鱼螈 Ichthyophis bannanicus & (3) \\
\hline 有尾目 & Caudata & & & \\
\hline 隐鳃鲵科 & Cryptobranchidae & 大鲵属 Andrias & 2 中国大鲵 Andrias davidianus & (2) \\
\hline \multirow[t]{6}{*}{ 小鲵科 } & Hynobiidae & 山溪鲵属 Batrachuperus & 3 无斑山溪鲵 Batrachuperus karlschmidti & (3) \\
\hline & & & 4 山溪鲵 Batrachuperus pinchonii & (3) \\
\hline & & 拟小鲵属 Pseudohynobius & 5 贵州拟小鲵 Pseudohynobius guizhouensis & (2) \\
\hline & & 小鲵属 Hynobius & 6 猫儿山小鲵 Hynobius maoershanensis & (2) \\
\hline & & 拟小鲵属 Pseudohynobius & 7 宽阔水拟小鲵 Pseudohynobius kuankuoshuiensis & (3) \\
\hline & & & 8 水城拟小鲵 Pseudohynobius shuichengensis & (1) \\
\hline \multirow[t]{20}{*}{ 蝶螈科 } & Salamandridae & 蝾螈属 Cynops & 9 呈贡蝾螈 Cynops chenggongensis & (2) \\
\hline & & & 10 蓝尾蝾螈 Cynops cyanurus & (3) \\
\hline & & & 11 滇螈 Cynops wolterstorffi & (2) \\
\hline & & 肥螈属 Pachytriton & 12 黑斑肥䗷 Pachytriton brevipes & (3) \\
\hline & & & 13 瑶山肥螈 Pachytriton inexpectatus & (2) \\
\hline & & & 14 莫氏肥螈 Pachytriton moi & (2) \\
\hline & & & 15 吴氏肥螈 Pachytriton wuguanfui & (1) \\
\hline & & 瘪螈属 Paramesotriton & 16 尾斑痃螈 Paramesotriton caudopunctatus & (3) \\
\hline & & & 17 富钟瘰螈 Paramesotriton fuzhongensis & (3) \\
\hline & & & 18 广西㾌螈 Paramesotriton guangxiensis & (2) \\
\hline & & & 19 无斑瘰螈 Paramesotriton labiatus & (2) \\
\hline & & & 20 尤里㾮螈 Paramesotriton longliensis & (1) \\
\hline & & & 21 茂兰㾮螈 Paramesotriton maolanensis & (1) \\
\hline & & & 22 武陵痋螈 Paramesotriton wulingensis & (2) \\
\hline & & & 23 织金㾌螈 Paramesotriton zhijinensis & (1) \\
\hline & & 疮螈属 Tylototriton & 24 细痣疮螈 Tylototriton asperrimus & (3) \\
\hline & & & 25 贵州疮螈 Tylototriton kweichowensis & (2) \\
\hline & & & 26 红㾮疮螈 Tylototriton shanjing & (3) \\
\hline & & & 27 棕黑疮螈 Tylototriton verrucosus & (2) \\
\hline & & & 28 滇南疮螈 Tylototriton yangi & (1) \\
\hline 无尾目 & Bombinatoridae & & & \\
\hline \multirow[t]{3}{*}{ 铃蟾科 } & Anura & 铃蟾属 Bombina & 29 大蹼铃蟾 Bombina maxima & (2) \\
\hline & & & 30 强婚刺铃蟾 Bombina fortinuptialis & (3) \\
\hline & & & 31 微蹼铃蟾 Bombina microdeladigitora & (2) \\
\hline \multirow[t]{7}{*}{ 蟾蜍科 } & Bufonidae & 蟾蜍属 Bufo & 32 哀牢溪蟾 Bufo ailaoanus & (2) \\
\hline & & & 33 无棘溪蟾 Bufo aspinius & (2) \\
\hline & & & 34 隐耳溪蟾 Bufo cryptotympanicus & (2) \\
\hline & & & 35 中华蟾蜍 Bufo gargarizans & (3) \\
\hline & & & 36 绿春溪蟾 Bufo uchunnicus & (2) \\
\hline & & & 37 孟连溪蟾 Bufo menglianus & (2) \\
\hline & & & 38 缅甸溪蟾 Bufo pageoti & (2) \\
\hline
\end{tabular}


王波, 黄勇, 李家堂, 戴强, 王跃招, 杨道德. 西南喀斯特地貌区两栖动物丰富度分布格局与环境因子的关 系. 生物多样性, 2018, 26 (9): 941-950.

http://www.biodiversity-science.net/CN/10.17520/biods.2018125

\begin{tabular}{|c|c|c|c|c|}
\hline & & 属名 & 物种名 & 分布 \\
\hline & & Genus & Species & Distribution \\
\hline & & & 39 疮棘溪蟾 Bufo tuberospinius & (2) \\
\hline & & 头棱蟾属 Duttaphrynus & 40 隆枕蟾蜍 Duttaphrynus cyphosus & (2) \\
\hline & & & 41 黑眶蟾蜍 Duttaphrynus melanostictus & (3) \\
\hline \multirow[t]{20}{*}{ 叉舌蛙科 } & Dicroglossidae & 陆蛙属 Fejervarya & 42 海陆蛙 Fejervarya cancrivora & (2) \\
\hline & & & 43 泽陆蛙 Fejervarya multistriata & (3) \\
\hline & & 虎纹蛙属 Hoplobatrachus & 44 虎纹蛙 Hoplobatrachus chinensis & (3) \\
\hline & & 大头蛙属 Limnonectes & 45 版纳大头蛙 Limnonectes bannaensis & (3) \\
\hline & & & 46 刘氏泰诺蛙 Limnonectes liui & (2) \\
\hline & & & 47 陇川大头蛙 Limnonectes longchuanensis & (2) \\
\hline & & 倭蛙属 Nanorana & 48 铜色棘肛蛙 Nanorana aenea & (2) \\
\hline & & & 49 察隅棘蛙 Nanorana chayuensis & (2) \\
\hline & & & 50 花棘蛙 Nanorana maculosa & (2) \\
\hline & & & 51 双团棘胸蛙 Nanorana phrynoides & (3) \\
\hline & & & 52 棘肛蛙 Nanorana unculuanus & (2) \\
\hline & & & 53 腹斑倭蛙 Nanorana ventripunctata & (2) \\
\hline & & & 54 云南棘蛙 Nanorana yunnanensis & (3) \\
\hline & & 浮蛙属 Occidozyga & 55 尖舌浮蛙 Occidozyga lima & (3) \\
\hline & & & 56 圆舌浮蛙 Occidozyga martensii & (3) \\
\hline & & 棘胸蛙属 Quasipaa & 57 棘腹蛙 Quasipaa boulengeri & (3) \\
\hline & & & 58 小棘蛙 Quasipaa exilispinosa & (3) \\
\hline & & & 59 棘侧蛙 Quasipaa shini & (3) \\
\hline & & & 60 棘胸蛙 Quasipaa spinosa & (3) \\
\hline & & & 61 多疮棘蛙 Quasipaa verrucospinosa & (2) \\
\hline \multirow[t]{6}{*}{ 雨蛙科 } & Hylidae & 雨蛙属 Hyla & 62 华西雨蛙 Hyla annectans & (3) \\
\hline & & & 63 中国雨蛙 Hyla chinensis & (3) \\
\hline & & & 64 华南雨蛙 Hyla simplex & (3) \\
\hline & & & 65 无斑雨蛙 Hyla immaculata & (3) \\
\hline & & & 66 三港雨蛙 Hyla sanchiangensis & (3) \\
\hline & & & 67 昭平雨蛙 Hyla zhaopingensis & (2) \\
\hline \multirow[t]{15}{*}{ 角蟾科 } & Megophryidae & 无耳蟾属 Atympanophrys & 68 大花无耳蟾 Atympanophrys gigantica & (2) \\
\hline & & 短腿蟾属 & 69 宽头短腿蟾 Brachytarsophrys carinense & (3) \\
\hline & & Brachytarsophrys & 70 川南短腿蟾 Brachytarsophrys & (1) \\
\hline & & & chuannanensis & \\
\hline & & & 71 费氏短腿蟾 Brachytarsophrys feae & (2) \\
\hline & & 拟髡蟾属 Leptobrachium & 72 哀牢髭蟾 Leptobrachium ailaonicum & (2) \\
\hline & & & 73 峨眉髭蟾 Leptobrachium boringii & (3) \\
\hline & & & 74 沙巴拟髭蟾 Leptobrachium chapaense & (2) \\
\hline & & & 75 广西拟髭蟾 Leptobrachium guangxiense & (3) \\
\hline & & & 76 华深拟髡蟾 Leptobrachium huashen & (2) \\
\hline & & & 77 雷山髭蟾 Leptobrachium leishanense & (2) \\
\hline & & & 78 腾冲拟蹗蟾 Leptobrachium tengchongense & (2) \\
\hline & & & 79 崇安髭蟾 Leptobrachium liui & (2) \\
\hline & & & 80 原髡蟾 Leptobrachium promustache & (2) \\
\hline & & 掌突蟾属 Leptolalax & 81 高山掌突蟾 Leptolalax alpinus & (3) \\
\hline
\end{tabular}


王波, 黄勇, 李家堂, 戴强, 王跃招, 杨道德. 西南喀斯特地貌区两栖动物丰富度分布格局与环境因子的关 系. 生物多样性, 2018, 26 (9): 941-950.

http://www.biodiversity-science.net/CN/10.17520/biods.2018125

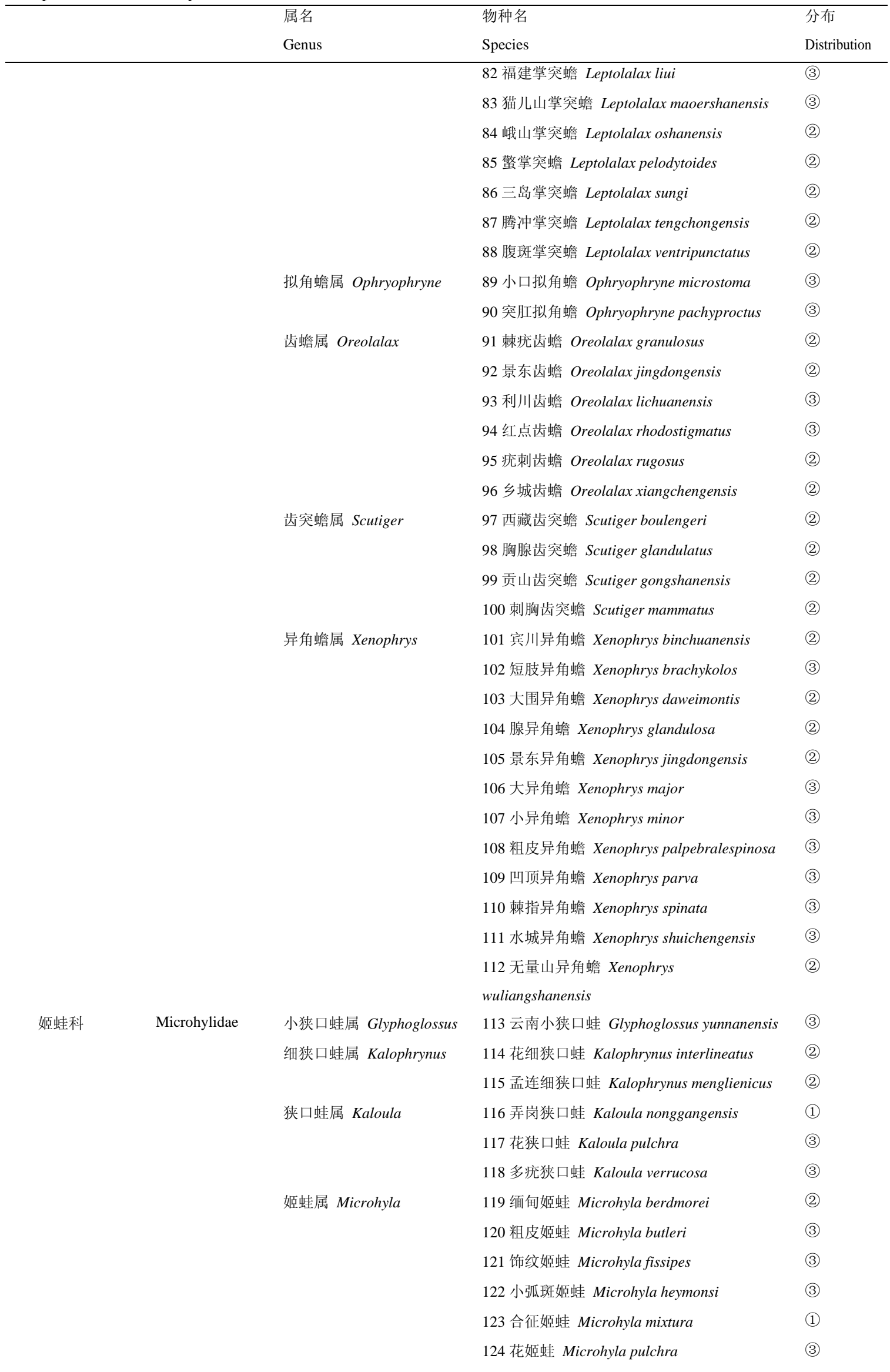


王波, 黄勇, 李家堂, 戴强, 王跃招, 杨道德. 西南喀斯特地貌区两栖动物丰富度分布格局与环境因子的关 系. 生物多样性, 2018, 26 (9): 941-950.

http://www.biodiversity-science.net/CN/10.17520/biods.2018125

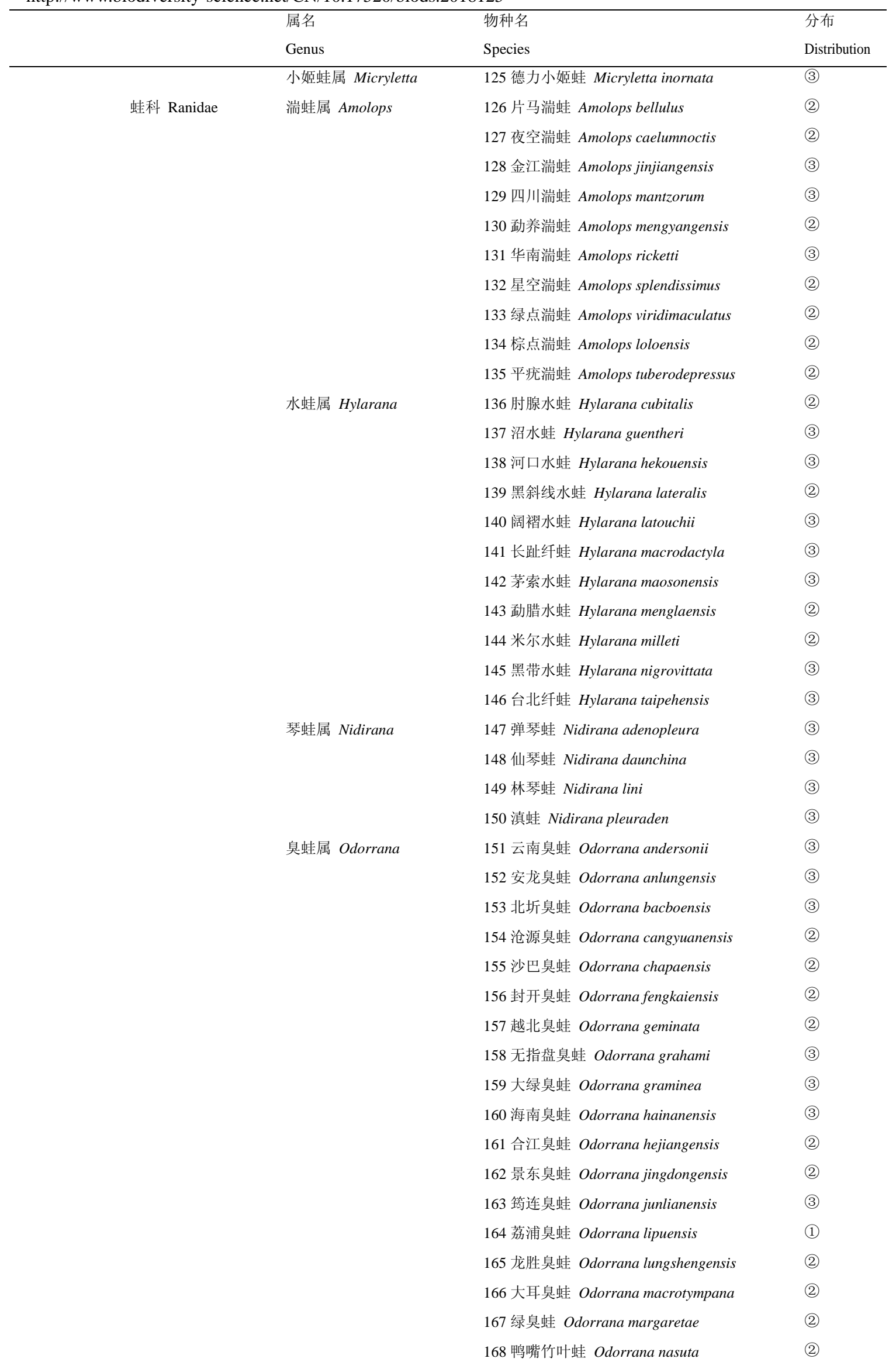


王波, 黄勇, 李家堂, 戴强, 王跃招, 杨道德. 西南喀斯特地貌区两栖动物丰富度分布格局与环境因子的关 系. 生物多样性, 2018, 26 (9): 941-950.

http://www.biodiversity-science.net/CN/10.17520/biods.2018125

\begin{tabular}{|c|c|c|c|}
\hline & 属名 & 物种名 & 分布 \\
\hline & Genus & Species & Distribution \\
\hline & & 169 圆斑臭蛙 Odorrana rotodora & (2) \\
\hline & & 170 花臭蛙 Odorrana schmackeri & (3) \\
\hline & & 171 滇南臭蛙 Odorrana tiannanensis & (2) \\
\hline & & 172 竹叶蛙 Odorrana versabilis & (3) \\
\hline & & 173 务川臭蛙 Odorrana wuchuanensis & (3) \\
\hline & & 174 安子山臭蛙 Odorrana yentuensis & (2) \\
\hline & 侧褶蛙属 Pelophylax & 175 黑斑侧褶蛙 Pelophylax nigromaculatus & (3) \\
\hline & 蛙属 Rana & 176 昭觉林蛙 Rana chaochiaoensis & (3) \\
\hline & & 177 徂徕林蛙 Rana culaiensis & (2) \\
\hline & & 178 寒露林蛙 Rana hanluica & (2) \\
\hline & & 179 越南趾沟蛙 Rana johnsi & (3) \\
\hline & & 180 猫儿山林蛙 Rana maoershanensis & (2) \\
\hline & & 181 胫腺蛙 Rana shuchinae & (2) \\
\hline & & 182 威宁蛙 Rana weiningensis & (3) \\
\hline 树蛙科 & 螳臂树蛙属 Chiromantis & 183 背条螳臂树蛙 Chiromantis doriae & (3) \\
\hline Rhacophoridae & 费树蛙属 Feihyla & 184 抚华费树蛙 Feihyla fuhua & (2) \\
\hline & & 185 白颊费树蛙 Feihyla palpebralis & (2) \\
\hline & & 186 侧条费树蛙 Feihyla vittata & (3) \\
\hline & 纤树蛙属 Gracixalus & 187 黑眼睑纤树蛙 Gracixalus gracilipes & (3) \\
\hline & & 188 金秀纤树蛙 Gracixalus jinxiuensis & (3) \\
\hline & & 189 弄岗纤树蛙 Gracixalus nonggangensis & (1) \\
\hline & 原指树蛙属 Kurixalus & 190 锯腿原指树蛙 Kurixalus odontotarsus & (3) \\
\hline & 刘树蛙属 Liuixalus & 191 金秀刘树蛙 Liuixalus jinxiuensis & (2) \\
\hline & & 192 罗默刘树蛙 Liuixalus romeri & (3) \\
\hline & & 193 十万大山刘树蛙 Liuixalus shiwandashan & (2) \\
\hline & 泛树蛙属 Polypedates & 194 凹顶泛树蛙 Polypedates impresus & (2) \\
\hline & & 195 斑腿泛树蛙 Polypedates megacephalus & (3) \\
\hline & & 196 无声囊泛树蛙 Polypedates mutus & (3) \\
\hline & 灌树蛙属 Raorchestes & 197 陇川灌树蛙 Raorchestes longchuanensis & (2) \\
\hline & & 198 预腊灌树蛙 Raorchestes menglaensis & (2) \\
\hline & 树蛙属 Rhacophorus & 199 缅甸树蛙 Rhacophorus burmanus & (3) \\
\hline & & 200 经甫树蛙 Rhacophorus chenfui & (3) \\
\hline & & 201 大树蛙 Rhacophorus dennysi & (3) \\
\hline & & 202 绿背树蛙 Rhacophorus dorsoviridis & (2) \\
\hline & & 203 棕褶树蛙 Rhacophorus feae & (2) \\
\hline & & 204 洪佛树蛙 Rhacophorus hungfuensis & (2) \\
\hline & & 205 黑蹼树蛙 Rhacophorus kio & (3) \\
\hline & & 206 老山树蛙 Rhacophorus laoshan & (2) \\
\hline & & 207 白线树蛙 Rhacophorus leucofasciatus & (3) \\
\hline & & 208 白领大树蛙 Rhacophorus maximus & (2) \\
\hline & & 209 侏树蛙 Rhacophorus minimus & (3) \\
\hline & & 210 黑点树蛙 Rhacophorus nigropunctatus & (3) \\
\hline & & 211 峨眉树蛙 Rhacophorus omeimontis & (3) \\
\hline & & 212 平龙树蛙 Rhacophorus pinglongensis & (1) \\
\hline
\end{tabular}


王波, 黄勇, 李家堂, 戴强, 王跃招, 杨道德. 西南喀斯特地貌区两栖动物丰富度分布格局与环境因子的关 系. 生物多样性, 2018, 26 (9): 941-950.

http://www.biodiversity-science.net/CN/10.17520/biods.2018125

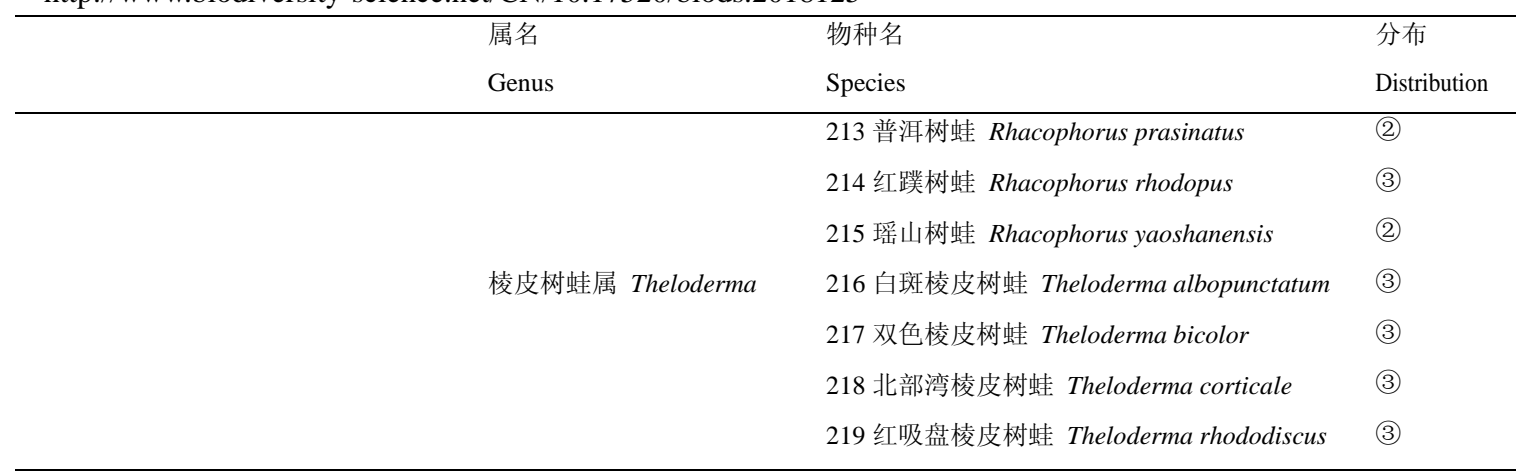

(1)仅分布于喀斯特地貌区; (2)仅分布于非喀斯特地貌区; (3)分布于喀斯特地貌和非喀斯特地貌区。

(1)Only distributed in karst landform regions;(2)Only distributed in non-karst landform regions;(3)Distributed in both karst landform and non-karst landform regions. 